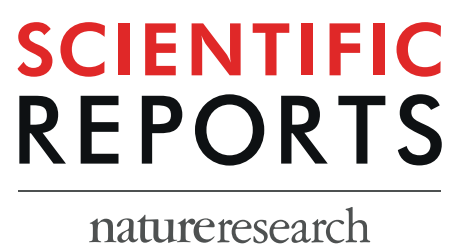

\title{
OPEN The gender dependent influence of sodium bicarbonate supplementation on anaerobic power and specific performance in female and male wrestlers
}

\author{
Krzysztof Durkalec-Michalski ${ }^{1,2 *}$, Emilia E. Zawieja ${ }^{1}$, Bogna E. Zawieja ${ }^{3}$, \\ Patrycja Michałowska ${ }^{1}$ \& Tomasz Podgórski ${ }^{4}$
}

The aim of this study was the assessment of progressive low-dose sodium bicarbonate $\left(\mathrm{NaHCO}_{3}\right)$ supplementation on the anaerobic indices in two bouts of Wingate tests (WT) separated by wrestlingspecific performance test and assessing the gender differences in response. Fifty-one (18 F) wrestlers completed a randomized trial of either a $\mathrm{NaHCO}_{3}$ (up to $100 \mathrm{mg} \cdot \mathrm{kg}^{-1}$ ) or a placebo for 10 days. Before and after treatment, athletes completed an exercise protocol that comprised, in sequence, the first $\mathrm{WT}_{1}$, dummy throw test (DT), and second $\mathrm{WT}_{2}$. The number of completed throws increased significantly in males from $19.3 \pm 2.6 \mathrm{NaHCO}_{3 \text { pre }}$ to $21.7 \pm 2.9 \mathrm{NaHCO}_{3 \text { post }}$. $\Delta \mathrm{WT}_{2}-\mathrm{WT}_{1}$ improved particularly in the midsection of 30-s WT on $\mathrm{NaHCO}_{3}$. However, no significant differences were found in peak power (PP), power drop (PD) and average power (AP) (analyzed separately for each WT), and $\Delta \mathrm{WT}_{2}-\mathrm{WT}_{1}$ in PP and $P D$. Interaction with gender was significant for $A P, P P$ and $P D$, every second of $\mathrm{WT}_{1}$ and $\mathrm{WT}_{2}$, as well as DT test. In conclusion, our study suggests that the response to $\mathrm{NaHCO}_{3}$ may be gender-specific and progressive low-dose $\mathrm{NaHCO}_{3}$ supplementation allows the advantageous strengthening of wrestlingspecific performance in males. It can also lead to maintenance of high anaerobic power mainly in the midsection of the 30-s Wingate test.

Dietary supplement use is greater in athletes than in the general population ${ }^{1}$. Some supplements, when ingested properly, can improve the athlete's health and performance, but others are taken even though they have no proved influence. One of the supplements whose effectiveness is indicated in International Olympic Committee (IOC) as well as International Society of Sports Nutrition statements, especially for high-performance athletes, is sodium bicarbonate $\left(\mathrm{NaHCO}_{3}\right)^{2,3}$. $\mathrm{NaHCO}_{3}$ supplementation increases extracellular bicarbonate concentration, which causes blood alkalosis ${ }^{4}$. Because of the greater $\mathrm{pH}$ gradient between the muscle cells and extracellular fluids, $\mathrm{H}^{+}$ produced during exercise are transported more easily leads to greater efflux of $\mathrm{H}^{+}$and $\mathrm{La}^{-}$from the exercising muscle $^{3-5}$. This is particularly important because intramuscular acidosis can cause muscular fatigue based on different mechanisms: (1) impaired glycolysis because of reduced activity of key enzymes such as glycogen phosphorylase and phosphofructokinase; (2) hindered muscle's contraction capacity due to the competition of $\mathrm{H}^{+}$ with calcium ions; (3) inhibition of oxidative phosphorylation; (4) compromised resynthesis of phosphocreatine at low $\mathrm{pH}^{6}$. The increase in buffer capacity by $\mathrm{NaHCO}_{3}$ supplementation can therefore allow to sustain muscle contractility during intense exercise and delay muscle fatigue ${ }^{5,6}$.

Improvements in performance contributed to increases in buffering capacity are likely confined to short and high-intensity tasks which can be limited by acid-base disturbances and combat sports are one of them. Wrestling is a high-intensity competitive sport discipline, in which glycolysis is a substantial energy system. For instance,

\footnotetext{
${ }^{1}$ Institute of Human Nutrition and Dietetics, Poznań University of Life Sciences, Poznań, 60-624, Poland. ${ }^{2}$ Department of Food and Nutrition, Poznań University of Physical Education, Poznań, 61-871, Poland. ${ }^{3}$ Department of Mathematical and Statistical Methods, Poznań University of Life Sciences, Poznań, 60-637, Poland. ${ }^{4}$ Department od Physiology and Biochemistry, Poznań University of Physical Education, Poznań, 61-871, Poland. *email: durkmich@up.poznan.pl
} 


\begin{tabular}{|c|c|c|c|c|c|c|c|c|}
\hline & & & \multicolumn{2}{|l|}{ Peak Power } & \multicolumn{2}{|c|}{ Power Drop } & \multicolumn{2}{|c|}{ Average Power } \\
\hline & & & $(\mathrm{W})$ & $\left(\mathrm{W} \cdot \mathrm{kg}^{-1}\right)$ & (W) & $\left(\mathrm{W} \cdot \mathrm{kg}^{-1}\right)$ & $(\mathrm{W})$ & $\left(\mathrm{W} \cdot \mathrm{kg}^{-1}\right)$ \\
\hline \multirow{8}{*}{ Females } & \multirow{2}{*}{$\mathrm{NaHCO}_{3 \text { pre }}$} & $\mathrm{WT}_{1}$ & $497 \pm 100$ & $9.3 \pm 1.2$ & $268 \pm 65$ & $5.0 \pm 0.9$ & $339 \pm 59$ & $6.3 \pm 0.7$ \\
\hline & & $\mathrm{WT}_{2}$ & $465 \pm 100$ & $8.7 \pm 1.1$ & $265 \pm 67$ & $5.0 \pm 1.1$ & $316 \pm 66$ & $5.8 \pm 0.8$ \\
\hline & \multirow{2}{*}{$\mathrm{NaHCO}_{3 \text { post }}$} & $\mathrm{WT}_{1}$ & $529 \pm 93$ & $9.9 \pm 0.9$ & $317 \pm 66$ & $5.9 \pm 0.9$ & $338 \pm 55$ & $6.3 \pm 0.5$ \\
\hline & & $\mathrm{WT}_{2}$ & $532 \pm 113$ & $9.8 \pm 1.1$ & $319 \pm 68$ & $6.0 \pm 0.9$ & $336 \pm 62$ & $6.2 \pm 0.7$ \\
\hline & \multirow{2}{*}{ PLA $_{\text {pre }}$} & $\mathrm{WT}_{1}$ & $622 \pm 107$ & $9.9 \pm 1.9$ & $354 \pm 105$ & $5.6 \pm 1.7$ & $413 \pm 48$ & $6.4 \pm 0.7$ \\
\hline & & $\mathrm{WT}_{2}$ & $591 \pm 110$ & $9.4 \pm 1.8$ & $314 \pm 122$ & $5.0 \pm 2.1$ & $416 \pm 45$ & $6.5 \pm 0.5$ \\
\hline & \multirow{2}{*}{ PLA $_{\text {post }}$} & $\mathrm{WT}_{1}$ & $646 \pm 112$ & $10.2 \pm 1.8$ & $379 \pm 105$ & $6.0 \pm 1.8$ & $421 \pm 41$ & $6.6 \pm 0.4$ \\
\hline & & $\mathrm{WT}_{2}$ & $627 \pm 121$ & $9.9 \pm 1.8$ & $359 \pm 97$ & $5.6 \pm 1.5$ & $406 \pm 57$ & $6.3 \pm 0.6$ \\
\hline \multirow{8}{*}{ Males } & \multirow{2}{*}{$\mathrm{NaHCO}_{3 \text { pre }}$} & $\mathrm{WT}_{1}$ & $1023 \pm 265$ & $13.1 \pm 2.5$ & $640 \pm 212$ & $8.2 \pm 2.3$ & $589 \pm 84$ & $7.5 \pm 0.5$ \\
\hline & & $\mathrm{WT}_{2}$ & $965 \pm 250$ & $12.3 \pm 2.4$ & $614 \pm 196$ & \begin{tabular}{|l|}
$7.8 \pm 1.9$ \\
\end{tabular} & $556 \pm 96$ & $7.0 \pm 0.8$ \\
\hline & \multirow{2}{*}{$\mathrm{NaHCO}_{3 \text { post }}$} & $\mathrm{WT}_{1}$ & $1089 \pm 244$ & $14.0 \pm 2.4$ & $704 \pm 194$ & \begin{tabular}{|l|}
$9.0 \pm 2.2$ \\
\end{tabular} & $592 \pm 92$ & $7.5 \pm 0.6$ \\
\hline & & $\mathrm{WT}_{2}$ & $1067 \pm 228$ & $13.7 \pm 2.0$ & $723 \pm 173$ & $9.3 \pm 2.0$ & $578 \pm 97$ & $7.3 \pm 0.7$ \\
\hline & \multirow{2}{*}{$\mathrm{PLA}_{\text {pre }}$} & $\mathrm{WT}_{1}$ & $954 \pm 322$ & $12.6 \pm 3.1$ & $608 \pm 255$ & \begin{tabular}{|l|}
$8.0 \pm 2.8$ \\
\end{tabular} & $564 \pm 131$ & $7.5 \pm 0.9$ \\
\hline & & $\mathrm{WT}_{2}$ & $897 \pm 270$ & $11.8 \pm 2.8$ & $584 \pm 194$ & $7.7 \pm 2.2$ & $540 \pm 126$ & $7.1 \pm 1.0$ \\
\hline & \multirow{2}{*}{ PLA $_{\text {post }}$} & $\mathrm{WT}_{1}$ & $990 \pm 267$ & $13.1 \pm 2.4$ & $646 \pm 193$ & $8.6 \pm 2.0$ & $569 \pm 128$ & $7.5 \pm 0.8$ \\
\hline & & $\mathrm{WT}_{2}$ & $935 \pm 238$ & $12.5 \pm 2.4$ & $629 \pm 173$ & $8.4 \pm 2.0$ & $542 \pm 128$ & $7.2 \pm 1.0$ \\
\hline
\end{tabular}

Table 1. Power characteristics before and after supplementation in female and male wrestlers. Data are presented at mean $\pm \mathrm{SD}$. $\mathrm{NaHCO}_{3 \text { pre }}$, before sodium bicarbonate supplementation; $\mathrm{NaHCO}_{3 \text { post }}$, after sodium bicarbonate supplementation; $\mathrm{PLA}_{\text {pre }}$, before placebo; $\mathrm{PLA}_{\text {post }}$, after placebo; $\mathrm{WT}_{1}$, the first Wingate test; $\mathrm{WT}_{2}$, the second Wingate test.

blood lactate concentrations rise up to $\sim 12.5 \mathrm{mmol} \cdot \mathrm{L}^{-1}$ after a simulated wrestling combat ${ }^{7}$. The anaerobic power is crucial to perform wrestling attacks, to lift and/or throw an opponent during offensive actions in wrestling, as well as to resist the opponent's attacks ${ }^{8}$. Thus, wrestling athletes would benefit from $\mathrm{NaHCO}_{3}$ notably. However, studies on $\mathrm{NaHCO}_{3}$ supplementation in wrestling are scarce. In judo, $\mathrm{NaHCO}_{3}$ caused a significant improvement in judo-specific performance, confirming its efficacy in intermittent supramaximal specific to discipline bouts of exercises, in which fatigue is evident ${ }^{9}$. The Special Judo Fitness Test (SJFT) result was improved in $0.3 \mathrm{~g} \cdot \mathrm{kg}^{-1}$ $\mathrm{NaHCO}_{3}$ than in placebo (PLA) treatment ${ }^{9}$. Furthermore, in striking disciplines such as boxing or taekwondo, the same dose of $\mathrm{NaHCO}_{3}$ increased exercise capacity related to the total punch efficacy ${ }^{10}$ or the attack time of a simulated taekwondo combat ${ }^{11}$, respectively. In contrary, in a study by Felippe et al. ${ }^{12}$ only combined treatment with $\mathrm{NaHCO}_{3}$ and caffeine resulted in significant increases in judo performance compared with PLA. In a previous study by our lab, a dose of up to $0.1 \mathrm{~g} \cdot \mathrm{kg}^{-1} \mathrm{NaHCO}_{3}$ had no effect on wrestling performance in specific dummy throw test (DT) compared to PLA ${ }^{13}$. However, even though the doses used in the study seemed to be too small to improve the power in two Wingate tests (WT) and the number of wrestling suplex throws, the time-to-peak power decreased significantly with $\mathrm{NaHCO}_{3}$, but only in the second $\mathrm{WT}^{13}$.

It is therefore possible that $\mathrm{NaHCO}_{3}$ supplementation effect is more pronounce later in the multiple-bout workout when the capacity of dealing with $\mathrm{H}^{+}$is significantly exhausted. For instance, in a study by Artioli et al. ${ }^{9}$ the improvement in peak and average power was observed only in the two final bouts of four 30-s upper body WTs ${ }^{9}$. Similarly, Tobias et al. ${ }^{14}$ observed that $\mathrm{NaHCO}_{3}$ improved mean power only in forth bout of 30-s upper WT by $\sim 9 \%$ and $\sim 14 \%$, respectively. Olivera et al. ${ }^{15}$ also noted an increase in total mechanical work done in the last two bouts (bouts $3+4:+5.93 \%, p=0.02$ ) of four 30 -s sprints.

Since it seems that sodium bicarbonate may influence the latter bouts of high intensity exercise, we aimed at assessing the gender-related influence of progressive-dose $\mathrm{NaHCO}_{3}$ loading regimen on the difference in power between two bouts of Wingate tests separated by wrestling-specific exercise performance test, simulating combat during an intense competition round. We analyzed both genders separately since it seems possible that females respond to sodium bicarbonate to a lesser extent than males. That can result from the differences in muscle anatomy and physiology. On one hand men are usually stronger and more powerful, and on the other hand women are less fatigable ${ }^{16}$. Moreover, females have smaller type II fibers than $\operatorname{men}^{17,18}$, while males have greater glycolytic capacity ${ }^{19,20}$. Finally, the exercise-induced $\mathrm{pH}$ drop is also greater in males ${ }^{20}$. Therefore, we hypothesized that $\mathrm{NaHCO}_{3}$ supplementation in men will have a greater beneficial effect on muscle power and throwing performance.

\section{Results}

Wingate anaerobic power indices. The interaction with gender was significant for average power (AP) $(p<0.0001)$, power drop (PD) $(p<0.0001)$, and peak power (PP) $(p<0.0001)$. However, no significant differences in AP, PD and PP were found after $\mathrm{NaHCO}_{3}$ and PLA interventions neither in females nor in males (Table 1). There were no significant gender interactions for the differences between $\mathrm{WT}_{2}$ and $\mathrm{WT}_{1}\left(\Delta \mathrm{WT}_{2}-\mathrm{WT}_{1}\right)$ in $\mathrm{AP}, \mathrm{PD}$ and PP. $\triangle \mathrm{WT}_{2}-\mathrm{WT}_{1}$ in $\mathrm{AP}, \mathrm{PP}$ and $\mathrm{PD}$ were not significantly affected by $\mathrm{NaHCO}_{3}$ and PLA treatments in both genders (Table 2).

The interactions between treatment $\mathrm{x}$ period as regards power were significant in seconds $12(p=0.0106)$ and $16(p=0.0398)$ in all wrestlers. Gender interaction was significant in each second of WT. Moreover, gender $\mathrm{x}$ 


\begin{tabular}{|c|c|c|c|c|c|c|c|}
\hline & & \multicolumn{2}{|l|}{ Peak Power } & \multicolumn{2}{|l|}{ Power Drop } & \multicolumn{2}{|l|}{ Average Power } \\
\hline & & $(\mathrm{W})$ & $\left(\mathrm{W} \cdot \mathrm{kg}^{-1}\right)$ & $(\mathrm{W})$ & $\left(\mathrm{W} \cdot \mathrm{kg}^{-1}\right)$ & $(\mathrm{W})$ & $\left(\mathrm{W} \cdot \mathrm{kg}^{-1}\right)$ \\
\hline \multirow{4}{*}{ Females } & $\mathrm{NaHCO}_{3 \text { pre }}$ & $-32.5 \pm 57.1$ & $-0.6 \pm 1.1$ & $-3.0 \pm 48.1$ & $0.0 \pm 0.9$ & $-22.6 \pm 39.6$ & $-0.4 \pm 0.8$ \\
\hline & $\mathrm{NaHCO}_{3 \text { post }}$ & $2.6 \pm 28.2$ & $-0.1 \pm 0.4$ & $2.3 \pm 24.5$ & $0.0 \pm 0.5$ & $-1.5 \pm 17.4$ & $0.0 \pm 0.3$ \\
\hline & PLA $_{\text {pre }}$ & $-30.7 \pm 22.5$ & $-0.5 \pm 0.3$ & $-40.7 \pm 41.4$ & $-0.6 \pm 0.6$ & $3.8 \pm 11.6$ & $0.1 \pm 0.2$ \\
\hline & PLA $_{\text {post }}$ & $-18.4 \pm 55.2$ & $-0.3 \pm 0.9$ & $-19.8 \pm 52.2$ & $-0.4 \pm 0.8$ & $-14.6 \pm 23.9$ & $-0.2 \pm 0.4$ \\
\hline \multirow{4}{*}{ Males } & $\mathrm{NaHCO}_{3 \text { pre }}$ & $-57.6 \pm 106.3$ & $-0.8 \pm 1.4$ & $-26.1 \pm 108.3$ & $-0.4 \pm 1.4$ & $-32.7 \pm 42.8$ & $-0.4 \pm 0.6$ \\
\hline & $\mathrm{NaHCO}_{3 \text { post }}$ & $-22.6 \pm 103.8$ & $-0.3 \pm 1.3$ & $18.4 \pm 122.4$ & $0.3 \pm 1.6$ & $-14.5 \pm 28.6$ & $-0.2 \pm 0.4$ \\
\hline & PLA $_{\text {pre }}$ & $-57.8 \pm 120.5$ & $-0.8 \pm 1.5$ & $-24.0 \pm 129.6$ & $-0.4 \pm 1.7$ & $-23.3 \pm 60.3$ & $-0.3 \pm 0.8$ \\
\hline & PLA $_{\text {post }}$ & $-55.6 \pm 58.8$ & $-0.7 \pm 0.8$ & $-17.7 \pm 78.7$ & $-0.1 \pm 1.1$ & $-26.6 \pm 28.6$ & $-0.3 \pm 0.4$ \\
\hline
\end{tabular}

Table 2. The difference in power between $\mathrm{WT}_{2}$ and $\mathrm{WT}_{1}\left(\Delta \mathrm{WT}_{2}-\mathrm{WT}_{1}\right)$ before and after supplementation. Data are presented at mean $\pm \mathrm{SD}$. $\mathrm{NaHCO}_{3 \text { pre }}$, before sodium bicarbonate supplementation; $\mathrm{NaHCO}_{3 \text { post }}$, after sodium bicarbonate supplementation; PLA $_{\text {pre }}$, before placebo; PLA $_{\text {post }}$, after placebo.

treatment interaction was significant in seconds: $10(p=0.0343), 11(p=0.0438), 12(p=0.0153), 15(p=0.0461)$, $16(p=0.0365), 17(p=0.0280), 21(p=0.0248), 23(p=0.0377), 26(p=0.0474), 28(p=0.0304), 29(p=0.0181)$ and $30(p=0.0359)$. In females significant changes were observed in seconds: $1(p=0.0204), 12(p=0.0180)$, $21(p=0.0070), 25(p=0.0343), 28(p=0.0083), 29(p=0.0294)$ and $30(p=0.0463)$. In males in seconds: 12 $(p=0.0269), 16(p=0.0409)$ and $17(p=0.0082)$.

In all participants the difference in power indices between $\mathrm{WT}_{2}$ and $\mathrm{WT}_{1}\left(\Delta\right.$ power $\left.\mathrm{WT}_{2}-\mathrm{WT}_{1}\right)$ improved significantly $\mathrm{NaHCO}_{3 \text { post }}$ vs $\mathrm{NaHCO}_{3 \text { pre }}$ in seconds: $12(p=0.0413), 16(p=0.0199)$ and $21(p=0.0430)$ (Fig. 1a). Furthermore, $\Delta$ power $\mathrm{WT}_{2}-\mathrm{WT}_{1} \mathrm{NaHCO}_{3 \text { post }}$ was significantly lower than $\mathrm{PLA}_{\text {post }}$ in seconds: $12(p=0.0144)$, $16(p=0.0370), 17(p=0.0125)$ and $21(p=0.0166)$ (Fig. $2 \mathrm{a})$. In second $12 \Delta$ power $\mathrm{WT}_{2}-\mathrm{WT}_{1}$ decreased significantly on PLA (PLA post vs PLA pre $)(p=0.0368)$. The gender interactions were recorded in seconds: 13 $(p=0.0382), 17(p=0.0174), 18(p=0.0187), 22(p=0.0428), 24(p=0.0082), 25(p=0.0149), 26(p=0.0144)$, $27(p=0.0123), 28(p=0.0336)$ and $29(p=0.0349)$, respectively. In females $\Delta$ power $\mathrm{WT}_{2}-\mathrm{WT}_{1}$ increased significantly $\mathrm{NaHCO}_{3 \text { post }}$ vs $\mathrm{NaHCO}_{3 \text { pre }}$ only in second $21(p=0.0475)$ and was higher $\mathrm{NaHCO}_{3 \text { post }}$ than $\mathrm{PLA}_{\text {post }}$ $(p=0.0130)$ (Figs. $1 \mathrm{~b}$ and $2 \mathrm{~b})$. In second $12(p=0.0388), 21(p=0.0406), 28(p=0.0294)$ and $29(p=0.0279)$ $\Delta$ power $\mathrm{WT}_{2}-\mathrm{WT}_{1}$ decreased significantly on PLA ( $\left.\mathrm{PLA}_{\text {post }} \mathrm{vs} \mathrm{PLA}_{\text {pre }}\right)$. In males $\Delta$ power $\mathrm{WT}_{2}-\mathrm{WT}_{1}$ increased significantly $\mathrm{NaHCO}_{3 \text { post }}$ vs $\mathrm{NaHCO}_{3 \text { pre }}$ only in second $12(p=0.0488)$ and in second 17 was higher $\mathrm{NaHCO}_{3 \text { post }}$ than $\operatorname{PLA}_{\text {post }}(p=0.0063)$ (Figs. $1 \mathrm{c}$ and $2 \mathrm{c}$ ). Furthermore, in second $16(p=0.0316)$ and $17(p=0.0045) \Delta$ power $\mathrm{WT}_{2}-\mathrm{WT}_{1}$ decreased significantly on PLA ( $\left.\mathrm{PLA}_{\text {post }} \mathrm{vs} \mathrm{PLA}_{\text {pre }}\right)$.

Dummy throw test. The interactions between treatment $\mathrm{x}$ period was significant $(p<0.0297)$. In females the number of completed throws was unchanged $\mathrm{NaHCO}_{3 \text { pre }}$ vs $\mathrm{NaHCO}_{3 \text { post }}$ (from $18.2 \pm 2.8$ to $19.6 \pm 2.2$ throws, $p=0.3766$ ) (Fig. 3a). However in males, it increased significantly by $\sim 12 \%$ form $19.3 \pm 2.6$ to $21.7 \pm 2.9$ throws $(p<0.0001$, Fig. $3 c)$. No significant changes were also observed PLA pre $_{\text {vLA }}$ post $($ females: $p=0.9185$; males: $p=0.7174)$ and $\mathrm{NaHCO}_{3 \text { post }}$ vs PLA post $_{\text {(females: }} p=1.0000$; males: $\left.p=1.0000\right)$ (Fig. 3b,d).

Blood sample analysis. Before and after supplementation no significant differences in glucose, lactate and pyruvate concentrations were found neither for female nor for male wrestlers (Table 3 ).

\section{Discussion}

In this study we showed that progressive supplementation of up to $100 \mathrm{mg} \cdot \mathrm{kg}^{-1}$ sodium bicarbonate did not significantly influence AP, PD and PP characteristics in two Wingate tests. However, it improved power maintenance in the midsection of the 30-s Wingate test and performance in wrestling-specific dummy throw test. We observed that gender was a significant factor potentially influencing the effectiveness of such a treatment. Gender interaction was significant for AP, PD and PP, but possibly the dose was too small to elicit any significant improvement in those parameters in both males and females. Gender was also significant factor influencing the effect of $\mathrm{NaHCO}_{3}$ on power in each second of the Wingate test and on performance in DT test. What is interesting, males significantly increased the number of throws in DT test, while females did not. That may suggest that the response to $\mathrm{NaHCO}_{3}$ treatment is gender specific.

As previously observed, supplementation with $\mathrm{NaHCO}_{3}$ may improve performance in combat sports ${ }^{9-11}$. $\mathrm{NaHCO}_{3}$ resulted in improvement of boxing (punch efficacy: $\left.+5.4 \%\right)^{10}$, taekwondo (the total attack time in combat: $+13 \%)^{11}$ and judo (summed number of throws in three bouts of SJFT: +4 throws) ${ }^{9}$ specific performance, respectively. In contrast, in our study performance in wrestling-specific DT improved significantly on $\mathrm{NaHCO}_{3}$ with significant gender interaction. Then, when analysing genders separately we found that males increased the number of throws by $\sim 11 \%$ ( 2 throws), while no significant changes were observed in females. This slight, yet important change could contribute to winning in real wrestling competition. Previous studies on $\mathrm{NaHCO}_{3}$ in combat sports did not include female athletes ${ }^{9-12}$.

Gender differences in response to $\mathrm{NaHCO}_{3}$ supplementation are especially worth discussing. Papers with female subjects are scarce. Only one of six studies on women showed the improvement after $\mathrm{NaHCO}_{3}$ intake $\mathrm{H}^{21-26}$. Kozak-Collins et al. ${ }^{21}$ supplemented seven competitive female cyclists with either $300 \mathrm{mg} \cdot \mathrm{kg}^{-1} \mathrm{NaHCO}_{3}$ or PLA $(\mathrm{NaCl}) .2 \mathrm{~h}$ after ingestion participants performed interval cycling protocol consisting of repeating intervals of $1 \mathrm{~min} 95 \% \mathrm{VO}_{2}$ max cycling and $1 \mathrm{~min}$ recovery at $60 \mathrm{~W}$ until exhaustion. They did not find any improvement in the 



Figure 1. Difference in power indices between $\mathrm{WT}_{2}$ and $\mathrm{WT}_{1}$ before and after $\mathrm{NaHCO}_{3}$ supplementation. (a) In all participants, $(\mathbf{b})$ in females, $(\mathbf{c})$ in males. Data are presented at mean $\pm \mathrm{SD}$. ${ }^{*} \mathrm{NaHCO}_{3 \text { post }}$ significantly different from $\mathrm{NaHCO}_{3 \text { pre }}$.

number of completed intervals. In comparison, Price et al. ${ }^{27}$ recruited only male subjects. Investigators also gave them $\mathrm{NaHCO}_{3}$ or PLA $(\mathrm{NaCl})$ before testing. Participants did two intermittent cycling trials comprised of repeated 3-min blocks ( $90 \mathrm{~s}$ at $40 \% \mathrm{VO}_{2} \max , 60 \mathrm{~s}$ at $60 \% \mathrm{VO}_{2} \mathrm{max}, 14$-s maximal sprint, 16 -s rest). Authors found that compared to PLA, power output was greater throughout exercise during the $\mathrm{NaHCO}_{3}$ trial. Tiryaki and Atterbom ${ }^{22}$ assessed the effect of $\mathrm{NaHCO}_{3}$ on $600 \mathrm{~m}$ running time of trained females and found no differences $(121.5 \mathrm{~s}$ on $\mathrm{NaHCO}_{3}$ and $120.4 \mathrm{~s}$ on PLA). On the other hand, males improved running time in $400 \mathrm{~m}$ distance by $1.52 \mathrm{~s}$ on $\mathrm{NaHCO}_{3}$ and in $800 \mathrm{~m}$ by $2.9 \mathrm{~s}^{28,29}$. Even though there are no studies assessing the effect of $\mathrm{NaHCO}_{3}$ on $600 \mathrm{~m}$ run in males, it can be expected that it would be also improved. Then, there are four studies on female team sports players ${ }^{23-26}$. Macutkiewicz and Sunderland ${ }^{23}$ observed no influence of $\mathrm{NaHCO}_{3}$ on Field Hockey Skill Tests and 

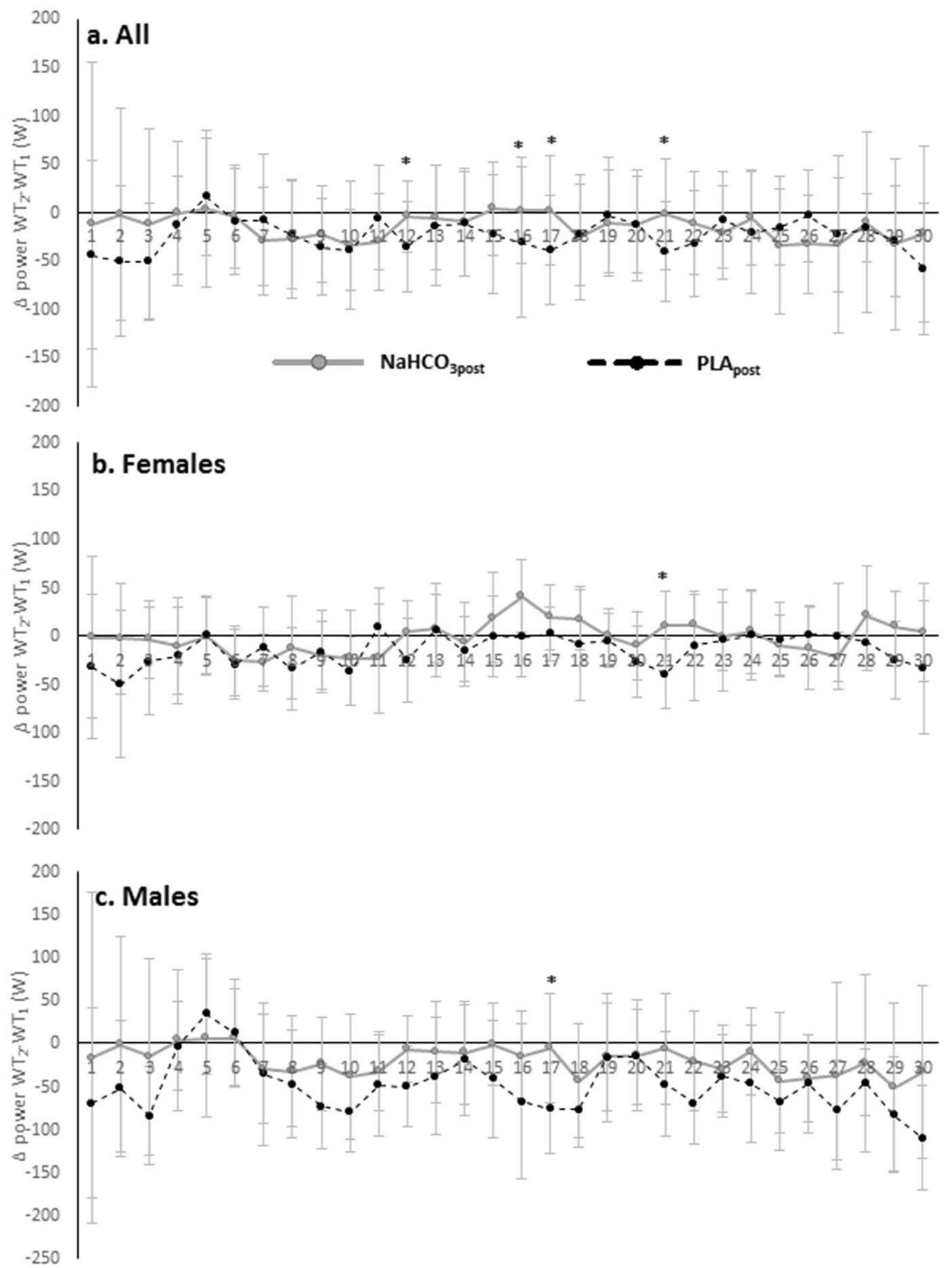

Figure 2. Difference in power indices between $\mathrm{WT}_{2}$ and $\mathrm{WT}_{1}\left(\Delta \mathrm{WT}_{2}-\mathrm{WT}_{1}\right)$ in $\mathrm{NaHCO}_{3 \text { post }}$ vs $\mathrm{PLA}_{\text {post }}(\mathbf{a})$ in all participants, $(\mathbf{b})$ in females, $(\mathbf{c})$ in males. Data are presented at mean $\pm \mathrm{SD}$. $* \mathrm{NaHCO}_{3 \text { post }}$ significantly different from PLA post .

the Loughborough Intermittent Shuttle Test in elite female field hockey players. In comparison, Krustrup et al. ${ }^{30}$ found $14 \%$ improvement in Yo-Yo intermittent recovery test level 2 performance $\left(735 \pm 61 \mathrm{~m}\right.$ on $\mathrm{NaHCO}_{3} \mathrm{vs}$ $646 \pm 46 \mathrm{~m}$ on PLA) in trained males. Moreover, Ducker et al..$^{31}$ and Miller et al. ${ }^{32}$ observed improved repeated sprint capacity in males on $\mathrm{NaHCO}_{3}$. In a study by Ducker et al. ${ }^{31}$ subjects did three sets of $6 \times 20 \mathrm{~m}$ sprints with 4 min of recovery between sets. $\mathrm{NaHCO}_{3}$ resulted in the best repeated-sprint performance. In a study by Miller et al. ${ }^{32}$ male athletes were given $\mathrm{NaHCO}_{3}$ or PLA and then performed repeated sprint cycling protocol comprising $10 \times 6 \mathrm{~s}$ sprints with $60 \mathrm{~s}$ recovery. Total work completed during the repeated sprint protocol was higher in the $\mathrm{NaHCO}_{3}$ condition $(69.8 \pm 11.7 \mathrm{~kJ})$ compared with both - the control $(59.6 \pm 12.2 \mathrm{~kJ})$ and PLA $(63.0 \pm 8.3 \mathrm{~kJ})$ conditions. In a study on female team sports athletes $\mathrm{NaHCO}_{3}$ failed to improve total work in prolonged intermittent 


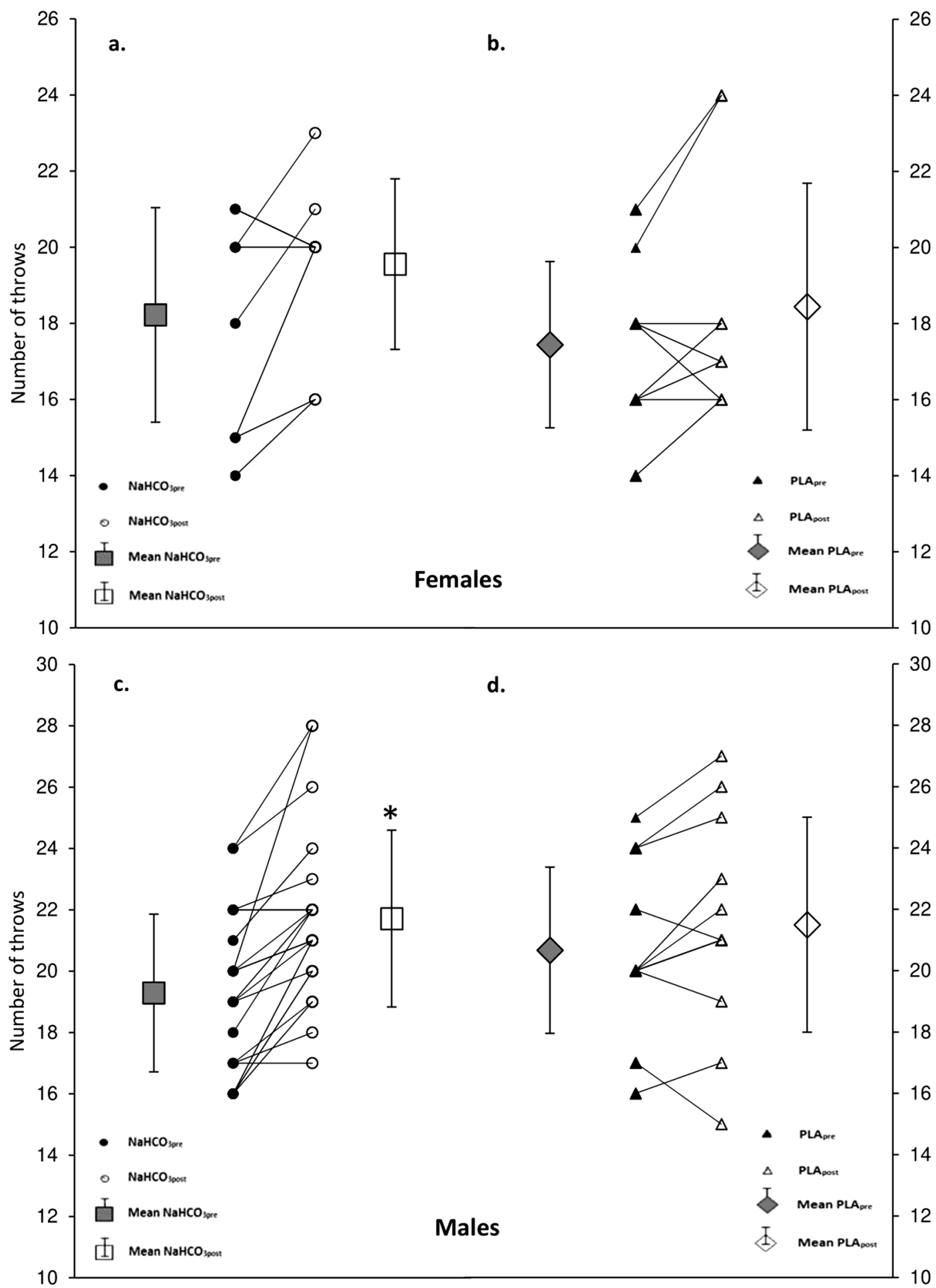

Figure 3. Total number of throws in dummy throw test. (a) In females before and after $\mathrm{NaHCO}_{3}$, (b) in females before and after PLA, (c) in males before and after $\mathrm{NaHCO}_{3},(\mathbf{d})$ in males before and after PLA. Data are presented at mean $\pm \mathrm{SD}$, and individual raw data. ${ }^{*} \mathrm{NaHCO}_{3 \text { post }}$ significantly different from $\mathrm{NaHCO}_{3 \text { pre }}$.

sprint performance (IST) ${ }^{24}$. IST consisted of two 36-min "halves" of repeated $~ 2$-min blocks: all-out 4-s sprint, $100 \mathrm{~s}$ of active recovery at $35 \% \mathrm{VO}_{2} \mathrm{max}$, and $20 \mathrm{~s}$ of rest. There was a trend toward improved total work in the second half, but it did not reach statistical significance $(p=0.08)$. Similarly, no improvement was observed in female water-polo players ${ }^{25}$. After the ingestion of $\mathrm{NaHCO}_{3}$ or PLA the subjects performed a 59-min match-simulation test (MST) that included $56 \times 10 \mathrm{~m}$ maximal-sprint swims. $\mathrm{NaHCO}_{3}$ increased blood $\mathrm{pH}$, but failed to improve mean sprint times. The only study to show improvement on $\mathrm{NaHCO}_{3}$ in female athletes is a study by Delextrat et al. ${ }^{26}$. Participants in that study were university basketball players. The supplementation protocol differed from 


\begin{tabular}{|c|c|c|c|c|c|c|c|}
\hline & & \multicolumn{2}{|c|}{ Glucose $\left(\mathrm{mg} \cdot \mathrm{dL}^{-1}\right)$} & \multicolumn{2}{|c|}{ Lactate $\left(\mathrm{mmol} \cdot \mathrm{L}^{-1}\right)$} & \multicolumn{2}{|c|}{ Pyruvate $\left(\mathrm{mmol} \cdot \mathrm{L}^{-1}\right)$} \\
\hline & & PRE $_{\text {exercise }}$ & POST $_{\text {exercise }}$ & PRE $_{\text {exercise }}$ & POST $_{\text {exercise }}$ & PRE $_{\text {exercise }}$ & POST $_{\text {exercise }}$ \\
\hline \multirow{4}{*}{ Females } & $\mathrm{NaHCO}_{3 \text { pre }}$ & $125.1 \pm 8.6$ & $137.4 \pm 25.0$ & $1.6 \pm 0.4$ & $15.9 \pm 1.9$ & $0.24 \pm 0.05$ & $0.62 \pm 0.09$ \\
\hline & $\mathrm{NaHCO}_{3 \text { post }}$ & $104.2 \pm 26.2$ & $117.3 \pm 28.7$ & $1.6 \pm 0.4$ & $14.4 \pm 5.4$ & $0.29 \pm 0.07$ & $0.53 \pm 0.13$ \\
\hline & $\mathrm{PLA}_{\text {pre }}$ & $122.7 \pm 19.7$ & $135.1 \pm 26.2$ & $1.8 \pm 0.8$ & $14.8 \pm 2.2$ & $0.26 \pm 0.06$ & $0.62 \pm 0.09$ \\
\hline & PLA $_{\text {post }}$ & $110.8 \pm 20.6$ & $120.6 \pm 34.7$ & $1.6 \pm 0.8$ & $14.4 \pm 3.3$ & $0.25 \pm 0.09$ & $0.51 \pm 0.11$ \\
\hline \multirow{4}{*}{ Males } & $\mathrm{NaHCO}_{3 \text { pre }}$ & $107.0 \pm 25.6$ & $123.6 \pm 34.0$ & $1.5 \pm 0.7$ & $15.9 \pm 3.5$ & $0.21 \pm 0.06$ & $0.51 \pm 0.14$ \\
\hline & $\mathrm{NaHCO}_{3 \text { post }}$ & $113.8 \pm 23.4$ & $134.7 \pm 29.5$ & $1.5 \pm 0.5$ & $16.5 \pm 4.0$ & $0.20 \pm 0.04$ & $0.54 \pm 0.14$ \\
\hline & $\mathrm{PLA}_{\text {pre }}$ & $124.1 \pm 20.7$ & $135.5 \pm 22.5$ & $2.1 \pm 0.9$ & $17.1 \pm 3.0$ & $0.22 \pm 0.07$ & $0.52 \pm 0.17$ \\
\hline & PLA ${ }_{\text {post }}$ & $113.6 \pm 9.2$ & $136.0 \pm 19.4$ & $2.0 \pm 0.8$ & $16.7 \pm 2.6$ & $0.22 \pm 0.08$ & $0.52 \pm 0.05$ \\
\hline
\end{tabular}

Table 3. Glucose, lactate and pyruvate concentrations before and after exercise tests in female and male wrestlers. Data are presented at mean \pm standard deviation $(\mathrm{SD}) . \mathrm{NaHCO}_{3 \text { pre }}$, before sodium bicarbonate supplementation; $\mathrm{NaHCO}_{3 \text { post }}$, after sodium bicarbonate supplementation; PLA pre , before placebo; PLA post $_{\text {, after }}$ placebo.

all other studies. Athletes were supplemented with higher dose of $\mathrm{NaHCO}_{3}\left(0.4 \mathrm{~g} \cdot \mathrm{kg}^{-1}\right.$ compared to $\left.0.3 \mathrm{~g} \cdot \mathrm{kg}^{-1}\right)$ and it was a multiday ( 3 days) loading. $\mathrm{NaHCO}_{3}$ improved mean values of sprint times, circuit times and jump height compared with PLA.

In summary, out of six trials on female athletes only in one $\mathrm{NaHCO}_{3}$ was proven to be effective ${ }^{21-26}$. On the other hand, males seem to benefit more from the supplementation ${ }^{27-32}$. The reason for that might be in physiological differences. Females have smaller type II fibers than men ${ }^{17,18}$. Type II fibers rely predominantly on glycolytic energy system. It was shown that males have greater glycolytic capacity ${ }^{19,20}$. In addition, in females $\mathrm{pH}$ drops to a lesser extent that in males during the same type of exercise ${ }^{20}$. All of that would explain the gender differences in the response to $\mathrm{NaHCO}_{3}$ supplementation observed in our and all previous studies.

Furthermore, it is important to observe that several bouts of intense exercise cause muscular fatigue, which may hamper performance during competition or training. In our study, power characteristics in $\mathrm{WT}_{1}$ tended to be higher than in $\mathrm{WT}_{2}$ (Table 1). One of the factors contributing to fatigue is a decrease in intramuscular $\mathrm{pH}$, which causes reduction in enzyme activation, competitive binding of $\mathrm{H}^{+}$to the active site of troponin, inhibition of oxidative phosphorylation and compromised resynthesis of phosphocreatine ${ }^{6}$. Sodium bicarbonate supplementation results in better buffering capacity of blood, which may increase the efflux of $\mathrm{H}^{+}$and $\mathrm{La}^{-}$out of muscle cells and decrease acidosis ${ }^{4}$.

It was previously established that the effect of $\mathrm{NaHCO}_{3}$ supplementation may be pronounced predominantly in latter stages of exercise ${ }^{9,13-15}$. Artioli et al. ${ }^{9}$ supplemented their athletes with $300 \mathrm{mg} \cdot \mathrm{kg}^{-1} \mathrm{NaHCO}_{3} 2 \mathrm{~h}$ before exercise. The performance test included four bouts of 30-s upper body WT tests. The significant changes in AP and PP were observed only in the two final bouts. This was attributed to improved resynthesis of phosphocreatine due to alkalosis caused by $\mathrm{NaHCO}_{3}$ supplementation, since low intramuscular $\mathrm{pH}$ may hamper this process ${ }^{9}$.

Tobias et al. ${ }^{14}$ assessed the effect of one week $\mathrm{NaHCO}_{3}$ ingestion on four-bout upper-body WT performance. Single bout was 30 s long with the load of $5 \%$ body mass. Seven-day supplementation resulted in $8 \%$ increase in total work done (in all four bouts summed). However, when the bouts were analysed separately a significant increase in AP and PP was present only in the last bout $(+9.4 \%, p=0.038 \text {, and }+13.7 \%, p=0.018 \text {, respectively })^{14}$.

A subsequent study by Oliveira et al. ${ }^{15}$ confirmed those results. They adopted a similar protocol of performance testing (four 30-s WT bouts for upper body interspersed by 3-min recovery) and also observed a significant increase in the total work done $(+2.86 \%, p=0.02)$ after 5 -day $\mathrm{NaHCO}_{3}$ supplementation compared to PLA. And again the difference was more pronounced in the last two bouts (sum of bout 3 and $4:+5.93 \%, p=0.02$ ).

Since aforementioned studies ${ }^{9,14,15}$ showed that the effect of $\mathrm{NaHCO}_{3}$ is apparent the most in latter stages of intense exercise, we aimed at assessing the gender-related effect of $\mathrm{NaHCO}_{3}$ on the difference between the first and the second WT, which were additionally interspersed by DT. Dummy throw test is a highly strenuous test, specific to wrestling. It is comprised of two alternating modes - slow and fast ${ }^{13}$. The slow mode lasts $30 \mathrm{~s}$, during which an athlete does four compulsory dummy throws. Whereas, in the quick mode an athlete performs as many throws as possible in $15 \mathrm{~s}$. The test lasts $3 \mathrm{~min}$ and comprises four slow and four quick modes, so that it is highly exhausting. Thus, the participants of our study were already fatigued on the onset of the second WT. Even though the difference in $\mathrm{PP}_{\text {between }} \mathrm{WT}_{2}$ and $\mathrm{WT}_{1}$ tended to be improved by $\mathrm{NaHCO}_{3}$ (by $35.1 \mathrm{~W}$ and $35.0 \mathrm{~W}$ in females and males, respectively), they were not statistically significant (Table 2).

Furthermore, innovative analysing (in the field of $\mathrm{NaHCO}_{3}$ supplementation) of each second of WTs separately significant improvement $\left(\mathrm{NaHCO}_{3 \text { post }}\right.$ vs $\left.\mathrm{NaHCO}_{3 \text { pre }}\right)$ in the difference in power between $\mathrm{WT}_{2}$ and $\mathrm{WT}_{1}$ were observed in seconds $12^{\text {th }}, 16^{\text {th }}$ and $21^{\text {st }}$ when all participants were taken together. In females the significant difference was apparent only in $21^{\text {st }} \mathrm{s}\left(\mathrm{NaHCO}_{3 \text { post }}\right.$ vs $\left.\mathrm{NaHCO}_{3 \text { pre }}\right)$, whereas in males in $12^{\text {th }} \mathrm{s}\left(\mathrm{NaHCO}_{3 \text { post }}\right.$ vs $\mathrm{NaHCO}_{3 \text { pre }}$ ). Compared to PLA, on $\mathrm{NaHCO}_{3}$ the difference in power between $\mathrm{WT}_{2}$ and $\mathrm{WT}_{1}$ improved in seconds $12^{\text {th }}, 16^{\text {th }}, 17^{\text {th }}$ and $21^{\text {st }}$ in all participants. In females, significant improvement was observed in $21^{\text {st }} s$ and in males in $17^{\text {th }}$ s $\left(\mathrm{NaHCO}_{3 \text { post }}\right.$ vs $\left.\mathrm{PLA}_{\text {post }}\right)$. It therefore seems reasonable to emphasize that most of the substantial effects were observed in the case of this supplementation protocol in the middle (12-21s) of the WTs.

In spite of the few significant differences observed in our study, we hypothesise that the dosage of $\mathrm{NaHCO}_{3}$ might have been too small for female and male wrestlers to elicit more apparent improvements. We used up to $100 \mathrm{mg} \cdot \mathrm{kg}^{-1} \mathrm{NaHCO}_{3}$ in days 8-10 of supplementation (Fig. 4). The dosage was well tolerated and did not cause any gastrointestinal (GI) problems, but the effectiveness was slight and moderate. Simultaneously, in previous 


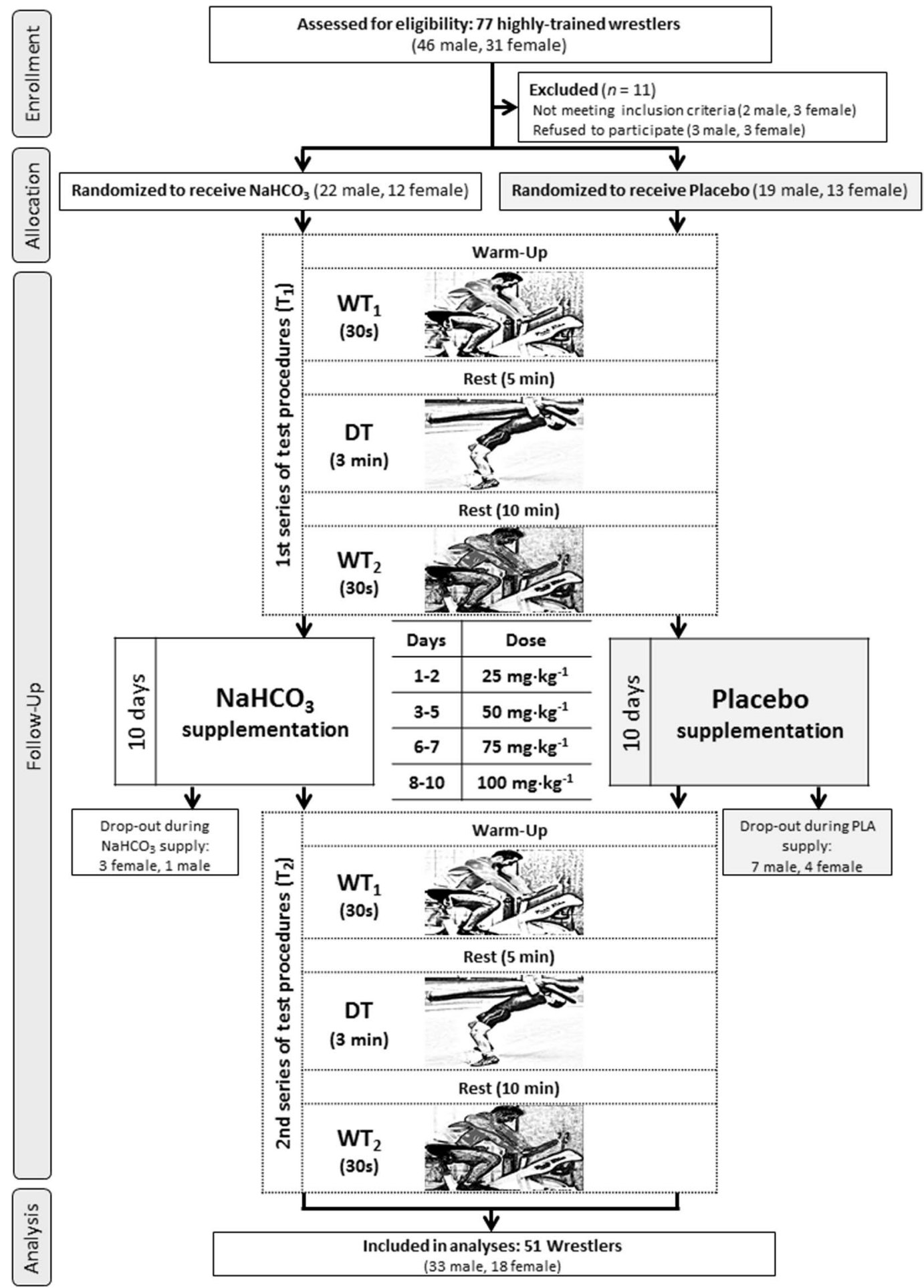

Figure 4. Flowchart of the study design.

studies higher doses were usually implemented ${ }^{9,14,15,33}$. IOC recommends the intake of $200-400 \mathrm{mg} \cdot \mathrm{kg}^{-1} \mathrm{NaHCO}_{3}$ 60-150 min prior to exercise ${ }^{3}$. However, in many athletes these doses result in GI distress ${ }^{34}$. This may prevent the practical use of supplementation with this compound in the conditions of natural high-intensity effort that is carried out, e.g. in combat sports. On the other hand, smaller doses might be ineffective. For instance, in nine healthy males the dose of $100 \mathrm{mg} \cdot \mathrm{kg}^{-1}$ failed to induce alkalosis, increase base excess and had no influence on work output ${ }^{35}$. Furthermore, in six males McKenzie et al. ${ }^{36}$ showed that even though induced alkalosis was greater with 300 than $150 \mathrm{mg} \cdot \mathrm{kg}^{-1} \mathrm{NaHCO}_{3}$, there were no differences in work produced (133.5 and $133.1 \mathrm{~kJ}$, respectively) and time to fatigue in the last bout (106 and 110s) between those two doses. However, comparing all those results to ours is limited because all of them used acute supplementation protocol, while participants in our study 


\begin{tabular}{|l|l|l|l|l|}
\hline & \multicolumn{3}{|l|}{ Females } & \multicolumn{2}{l|}{ Males } \\
\cline { 2 - 5 } & $\begin{array}{l}\mathbf{N a H C O}_{3} \\
(\mathbf{n}=9)\end{array}$ & $\begin{array}{l}\text { PLA } \\
(\mathbf{n}=\mathbf{9})\end{array}$ & $\begin{array}{l}\mathbf{N a H C O}_{3} \\
(\mathbf{n = 2 1})\end{array}$ & $\begin{array}{l}\text { PLA } \\
(\mathbf{n}=12)\end{array}$ \\
\hline Age (yrs) & $18.7 \pm 2.4$ & $18.1 \pm 2.6$ & $19.7 \pm 3.8$ & $19.5 \pm 4.4$ \\
\hline Body height $(\mathrm{cm})$ & $165 \pm 7$ & $169 \pm 6$ & $176 \pm 8$ & $174 \pm 7$ \\
\hline Body mass $(\mathrm{kg})$ & $53.7 \pm 5.1$ & $64.5 \pm 8.1$ & $78.8 \pm 13.1$ & $75.3 \pm 13.3$ \\
\hline FM (\%) & $17.3 \pm 3.0$ & $19.1 \pm 4.6$ & $11.5 \pm 4.2$ & $10.5 \pm 2.8$ \\
\hline FM (kg) & $9.4 \pm 2.5$ & $12.5 \pm 4.3$ & $9.4 \pm 4.8$ & $8.0 \pm 3.6$ \\
\hline FFM (\%) & $81.6 \pm 3.8$ & $82.1 \pm 6.4$ & $88.5 \pm 4.2$ & $89.7 \pm 3.0$ \\
\hline FFM (kg) & $44.3 \pm 3.1$ & $52.0 \pm 4.8$ & $69.2 \pm 9.5$ & $67.3 \pm 10.6$ \\
\hline TBW (\%) & $59.1 \pm 2.9$ & $55.9 \pm 3.6$ & $62.0 \pm 5.4$ & $63.0 \pm 3.5$ \\
\hline TBW (kg) & $31.6 \pm 1.5$ & $35.8 \pm 3.0$ & $48.7 \pm 6.3$ & $46.9 \pm 7.2$ \\
\hline
\end{tabular}

Table 4. Anthropometric characteristics of female and male wrestlers. Data are presented at mean \pm standard deviation (SD). FM, fat mass; FFM, fat-free mass; TBW, total body water content.

ingested $\mathrm{NaHCO}_{3}$ for ten days. In a previous study done by our lab, progressive-dose protocol of $\mathrm{NaHCO}_{3}$ up to $150 \mathrm{mg} \cdot \mathrm{kg}^{-1}$ was enough to improve CrossFit-like performance and ventilatory threshold ${ }^{37}$. However, $\mathrm{NaHCO}_{3}$ supplementation protocol similar to the one used in the current study (10 days, up to $100 \mathrm{mg} \cdot \mathrm{kg}^{-1}$ ) improved only time to PP in the second WT test with no further influence on anaerobic capacity and performance ${ }^{13}$. Nevertheless, we would like to highlight that in our research only highly-trained female and male wrestlers participated. Therefore, the observed changes related to males wrestling-specific performance and more effective maintenance of anaerobic power during high-intensity efforts, that can be considered beneficial at elite sport level, especially considering the short time duration of supplementation and a low dose of $\mathrm{NaHCO}_{3}$. It is worth bearing in mind, however, that a certain limitation to our study is the lack of verification of the bicarbonates concentration in the blood, which should be included in the subsequent studies, preferably in connection with the attempt to evaluate the effectiveness of supplementation of various doses of $\mathrm{NaHCO}_{3}$. Another limitation is the uneven distribution of participants in study groups. It is possible that if the number of participants was equal in each group the gender differences would be more pronounced.

\section{Conclusions}

Progressive low-dose $\mathrm{NaHCO}_{3}$ supplementation allows in combat sports the advantageous suppression of fatigue-induced power decline in the midsection of the 30-s Wingate test and improvement in wrestling specific dummy throw test. The response to $\mathrm{NaHCO}_{3}$ supplementation seems to be gender dependent. It appears that males can benefit more from the sodium bicarbonate supplementation, possibly because of physiological differences.

\section{Methods}

We would like to clarify that in this work we used the data previously collected in sodium bicarbonate studies involving wrestlers, which we conducted in our lab. We have already partially published the selected results obtained from most of the evaluated participants ${ }^{13}$. However, the data presented here was analyzed in a completely different fashion. The results for female and male wrestlers were analyzed separately to assess whether the response to the supplementation protocol may be determined by the gender of the athletes. We also focused on previously untouched aspects of the detailed change of power indices during each seconds of the Wingate test. Additional athletes were also included. Thus, we can unequivocally state that there is absolutely no risk of duplicate results, but we want to inform potential readers about the details of the data processing. Lastly, from a practical and scientific perspective, the research results which we have presented here are extremely valuable due to the innovative approach we have taken with $\mathrm{NaHCO}_{3}$ supplementation, the detailed analysis of performance indices herein, and the accompanying assessment of gender-related responses to $\mathrm{NaHCO}_{3}$ treatment.

Participants. Forty-six male and thirty-one female wrestlers were initially enrolled in this study. However, thirty-three male and eighteen female athletes participated in the study and were included in the analyses (Fig. 4). Anthropometric characteristics are presented in Table 4. The athletes were members of the Polish Wrestling National Team and/or competed in the highest level of Polish competitions. The inclusion criteria were good health, a valid medical clearance to participate in sports, a minimum of four years of combat sports experience, and doing at least four workout sessions (combat sport) a week. The exclusion criteria were current injury, any health condition preventing from participation, self-declared unwellness, and no interest in proper participation in study protocol.

All athletes reassured that they had not changed their life-styles, training regimen, diet or supplementation, and that they had not been using any medications and supplements with potential ergogenic effects, other than those supplied by the authors of this study. In accordance with the 1975 Declaration of Helsinki, before enrolment all participants had given their written consents to participate in the study protocol. Informed consents were also obtained from the parents of athletes under the age of 18 years, prior to participation in the study. The approval of the Bioethics Committee at Poznan University of Medical Sciences was obtained for this study. This trial was registered at Clinical Trials Gov (website: https://clinicaltrials.gov/ct2/show/NCT03406065; Clinical Trial Identification Number: NCT03406065). The study was registered retrospectively as registration was not 
required when the study enrolment started. The authors confirm that all ongoing and related trials associated with this intervention are registered. The study complies with the CONSORT statement for randomized trials, as shown in Fig. 4.

Study design and protocol. The study was designed as randomized double-blind placebo-controlled parallel-group trail. The supplementation period lasted ten days. The participants were familiarized with the exercise testing protocol and the equipment on a preliminary meeting with the research team. Anthropometric measurements were also taken on the same day. When enrolled athletes were randomly divided into the treatment groups (the $\mathrm{NaHCO}_{3}$ group or the PLA group). The random allocation sequence and matching were performed using stratified randomization via impartial biostatistics.

The experiment consisted of two separate visits $\left(\mathrm{T}_{1}-\mathrm{T}_{2}\right)$ for each participant. All testing was performed in natural conditions at the Central Olimpic Sports Centers (Spała, Zakopane) and Wrestling Training Centers (Poznań) in Poland. Throughout the study the participants were supplemented with either $\mathrm{NaHCO}_{3}$ or PLA. Exercise tests were conducted before and after each trial at the same time of day. Testing sessions started between 7.30 and 10.00 a.m. each time. To maintain constant conditions the participants were asked to refrain from any strenuous exercise for $24 \mathrm{~h}$ before the testing.

Supplementation. The participants were supplemented with $\mathrm{NaHCO}_{3}$ for ten consecutive days. Initial dose was much smaller than the dose recommended previously ${ }^{2,3}$ and was then increased gradually until $0.1 \mathrm{~g} \cdot \mathrm{kg}^{-1}$ was reached. This loading protocol was shown to eliminate any GI side effects ${ }^{13,37}$. Supplementation protocol is depicted in Fig. 4. Sodium bicarbonate was administered in the form of unmarked disc-shaped tablets (Alkala T, manufacturer-Sanum Kehlbeck GmbH \& Co. KG, Germany). The tablets were ingested with at least $250 \mathrm{~mL}$ of water and could either be swallowed or dissolved in the mouth. Maltodextrin with $\mathrm{NaCl}$ served as PLA. It was administered in a similar tablet prepared by the same producer as of the $\mathrm{NaHCO}_{3}$ tablets.

Daily doses of both $\mathrm{NaHCO}_{3}$ and PLA were split into three even portions. On training days, the tablets were ingested in the morning, in the evening, and $1.5 \mathrm{~h}$ before training session. On rest days, the supplements were administered in the morning, in the afternoon, and in the evening. To increase adherence the participants were also given personal supplementation plans.

Anthropometric measurements. Anthropometric measurements were taken in the fasted state in the preliminary visit in the morning. Body fat and free-fat mass were assessed based on air displacement plethys-

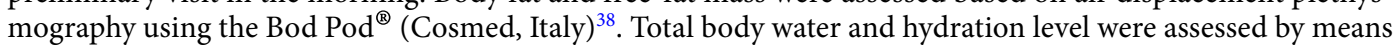
of bioelectric impedance, with Bodystat 1500 (Bodystat Inc., UK) ${ }^{39}$, and via urine specific gravity measurement, with URYXXON ${ }^{\circledR}$ Relax (Macherey-Nagel, Germany).

Exercise tests. Every testing session consisted of two Wingate anaerobic tests interspersed with a dummy throw test. Wrestling-specific performance capacity was measured using a specific dummy throw test described previously ${ }^{13}$. Wingate tests were performed on a cycloergometer (Monark 894E, Sweden). All recommendations for such tests as proposed by Bar-Or were strictly followed ${ }^{40}$. External loading was set at $7.5 \%$ body weight. The first WT $\left(\mathrm{WT}_{1}\right)$ was performed 5 min before DT and the second $\left(\mathrm{WT}_{2}\right) 10 \mathrm{~min}$ after DT (Fig. 4). Prior to testing all athletes completed 5-min warm-up on cycloergometer at approximately $50 \mathrm{~W}$ power. During the test, the athletes were verbally encouraged to exert maximum effort. The recorded results were analysed using the Monark Anaerobic Test Software (ver. 3.0.1, 2009, Monark, Sweden).

Blood samples analysis. Fingertip blood samples were taken twice, one sample before the $\mathrm{WT}_{1}$ and the other 3 min after the $\mathrm{WT}_{2}$. During blood draws the participants seated in an upright position. Blood samples were immediately transferred to microtubes containing $500 \mu \mathrm{L}$ of $0.6 \mathrm{M}$ perchloric acid. Glucose concentration was measured using a colorimetric enzymatic method with glucose oxidase (Liquick Cor-GLUCOSE, Cormay, Łomianki, Poland). Lactate and pyruvate measurements were performed according to the method described previously ${ }^{13}$. All biochemical analyses were conducted using a Synergy 2 SIAFRT microplate multi-detection reader (BioTek, USA).

Statistical analysis. The study was designed as a randomized parallel trial. Thus, in statistical analysis a mixed model of repeated measures with known error covariance matrix was used ${ }^{41,42}$. The random factor was participants nested in groups. Group stand for treatment $\left(\mathrm{NaHCO}_{3}\right.$ or PLA). Fixed factors were: period $\left(\mathrm{NaHCO}_{3 \text { pre-WT1 }}, \mathrm{NaHCO}_{3 \text { pre-WT2 }}, \mathrm{NaHCO}_{3 \text { post-WT1 }}, \mathrm{NaHCO}_{3 \text { post-WT2 }}, \mathrm{PLA}_{\text {pre-WT1 }}, \mathrm{PLA}_{\text {pre-WT2 }}, \mathrm{PLA}_{\text {post-WT1 }}\right.$, $\mathrm{PLA}_{\text {post-WT2 }}$ ), gender, times (period) (1-30 seconds of WT). Two-way interactions (gender $\times$ treatment, treatment $\times$ period, gender $\times$ period, and treatment $\times$ times (period)) and three-way interactions (gender $\times$ treatment $\times$ period, and gender $\times$ treatment $\times$ times (period)) were considered. Tested error covariance matrix structures included: Compound symmetry, Autocorrelation, Toeplitz and Unstructured. The choice of model with adequate covariance matrix structure was done according to Akaike information criterion ${ }^{43}$. Because gender and gender interactions with other factors were usually significant, those analyses were performed also for both genders separately. Statistical significance was set at $p<0.05$. The assumptions of normality and homoscedasticity was tested using the Shapiro-Wilk test for normality. If data did not meet the assumptions then the Box-Cox transformation was used. Data were analyzed by own calculations and using the SAS 9.3 software program. Effect size was calculated as Cohen's $f 2$, as follows: $\mathrm{f} 2=\mathrm{h} 2 /(1-\mathrm{h} 2)$. 
Ethical approval. All procedures performed were in accordance with the ethical standards of the institutional and national research committee and with the 1975 Helsinki declaration and its later amendments or comparable ethical standards.

\section{Practical Applications}

Our study suggests that 10-day progressive low-dose (from $0.025 \mathrm{~g} \cdot \mathrm{kg}^{-1}$ (days: $1-2$ ) up to $0.1 \mathrm{~g} \cdot \mathrm{kg}^{-1}$ (days: $\left.8-10\right)$ ) $\mathrm{NaHCO}_{3}$ supplementation allows the advantageous strengthening of wrestling-specific performance in males and suppression of fatigue-induced average power decline in combat sports, which is a result of specific physical efforts. It can also lead to maintenance of high anaerobic power mainly in the midsection of the 30-second Wingate test. Moreover, the higher dose could be more effective in this respect, which indicates that despite the lack of effect on GI functioning, doses lower than $0.1 \mathrm{~g} \cdot \mathrm{kg}^{-1} \mathrm{BM}$ do not seem to be effective in combat sports. It seems, however, that the response to $\mathrm{NaHCO}_{3}$ supplementation may be gender dependent, and males could be more prone to sodium bicarbonate supplementation.

\section{Data availability}

The datasets generated during and/or analysed during the current study are available in the figshare database repository (https://figshare.com/s/cf05c5daeb7e4b4f310e; https://doi.org/10.6084/m9.figshare.7907879).

Received: 8 July 2019; Accepted: 3 January 2020;

Published online: 05 February 2020

\section{References}

1. Knapik, J. J. et al. Prevalence of dietary supplement use by athletes: systematic review and meta-analysis. Sports Med. 46(1), 103-123 (2016).

2. Kerksick, C. M. et al. ISSN exercise \& sports nutrition review update: research \& recommendations. J. Int. Soc. Sports Nutr. 15(1), 38 (2018).

3. Maughan, R. J. et al. IOC Consensus Statement: Dietary supplements and the high-performance athlete. Br. J. Sports Med. 52, $439-455$ (2018).

4. Lancha Junior, A. H., Painelli Vde, S., Saunders, B. \& Artioli, G. G. Nutritional strategies to modulate intracellular and extracellular buffering capacity during high-intensity exercise. Sports Med. 45(1), 71-81 (2015).

5. Carr, A. J., Hopkins, W. G. \& Gore, C. J. Effects of acute alkalosis and acidosis on performance: a meta-analysis. Sports Med. 41(10), 801-814 (2011)

6. Heibel, A. B., Perim, P. H. L., Oliveira, L. F., McNaughton, L. R. \& Saunders, B. Time to optimize supplementation: modifying factors influencing the individual responses to extracellular buffering agents. Front. Nutr. 5, 35 (2018).

7. Karnincic, H., Tocilj, Z., Uljevic, O. \& Erceg, M. Lactate profile during greco-roman wrestling matchx. J. Sports Sci. Med. 8(CSSI3), 17-19 (2009)

8. Demirkan, E., Koz, M., Kutlu, M. \& Favre, M. Comparison of physical and physiological profiles in elite and amateur young wrestlers. J. Strength Cond. Res. 29(7), 1876-1883 (2015).

9. Artioli, G. G. et al. Does sodium-bicarbonate ingestion improve simulated judo performance? Int. J. Sport Nutr. Exerc. Metab. 17(2), 206-217 (2007)

10. Siegler, J. C. \& Hirscher, K. Sodium bicarbonate ingestion and boxing performance. J. Strength Cond. Res. 24(1), 103-108 (2010).

11. Lopes-Silva, J. P. et al. Sodium bicarbonate ingestion increases glycolytic contribution and improves performance during simulated taekwondo combat. Eur. J. Sport Sci. 18(3), 431-440 (2018).

12. Felippe, L. C., Lopes-Silva, J. P., Bertuzzi, R., McGinley, C. \& Lima-Silva, A. E. Separate and combined effects of caffeine and sodium bicarbonate intake on judo performance. Int. J. Sports Physiol. Perform. 11, 221-226 (2016).

13. Durkalec-Michalski, K. et al. The effect of a new sodium bicarbonate loading regimen on anaerobic capacity and wrestling performance. Nutrients. 10(6), pii: E697 (2018).

14. Tobias, G. et al. Additive effects of beta-alanine and sodium bicarbonate on upper-body intermittent performance. Amino Acids. 45(2), 309-317 (2013).

15. Oliveira, L. F. et al. Chronic lactate supplementation does not improve blood buffering capacity and repeated high-intensity exercise. Scand. J. Med. Sci. Sports. 27(11), 1231-1239 (2017).

16. Hunter, S. K. The relevance of sex differences in performance fatigability. Med. Sci. Sports Exerc. 48(11), 2247-56 (2016).

17. Simoneau, J. A. \& Bouchard, C. Human variation in skeletal muscle fiber-type proportion and enzyme activities. Am. J. Physiol. 257, E567-E572 (1989).

18. Porter, M. M., Stuart, S., Boij, M. \& Lexell, J. Capillary supply of the tibialis anterior muscle in young, healthy, and moderately active men and women. J. Appl. Physiol. 92(4), 1451-1457 (2002).

19. Tarnopolsky, M. A. Gender differences in substrate metabolism during endurance exercise. Can. J. Appl. Physiol. 25, 312-327 (2000).

20. Russ, D. W., Lanza, I. R., Rothman, D. \& Kent-Braun, J. A. Sex differences in glycolysis during brief, intense isometric contractions. Muscle Nerve. 32, 647-655 (2005).

21. Kozak-Collins, K., Burke, E. R. \& Schoene, R. B. Sodium bicarbonate ingestion does not improve performance in women cyclists. Med. Sci. Sports Exerc. 26, 1510-1515 (1994).

22. Tiryaki, G. R. \& Atterbom, H. A. The effects of sodium bicarbonate and sodium citrate on $600 \mathrm{~m}$ running time of trained females. J. Sports Med. Phys. Fitness. 35, 194-198 (1995).

23. Macutkiewicz, D. \& Sunderland, C. Sodium bicarbonate supplementation does not improve elite women's team sport running or field hockey skill performance. Physiol. Rep. 6, e13818 (2018).

24. Bishop, D. \& Claudius, B. Effects of induced metabolic alkalosis on prolonged intermittent-sprint performance. Med. Sci. Sports Exerc. 37, 759-767 (2005).

25. Tan, F. et al. Effects of induced alkalosis on simulated match performance in elite female water polo players. Int. J. Sport Nutr. Exerc. Metab. 20, 198-205 (2010).

26. Delextrat, A. et al. Effects of three-day serial sodium bicarbonate loading on performance and physiological parameters during a simulated basketball test in female university players. Int. J. Sport Nutr. Exerc. Metab. 28, 547-552 (2018).

27. Price, M., Moss, P. \& Rance, S. Effects of sodium bicarbonate ingestion on prolonged intermittent exercise. Med. Sci. Sports Exerc. 35, 1303-1208 (2003)

28. Goldfinch, J., Mc Naughton, L. \& Davies, P. Induced metabolic alkalosis and its effects on 400-m racing time. Eur. J. Appl. Physiol. Occup. Physiol. 57, 45-48 (1988).

29. Wilkes, D., Gledhill, N. \& Smyth, R. Effect of acute induced metabolic alkalosis on 800-m racing time. Med. Sci. Sports Exerc. 15, $277-280(1983)$ 
30. Krustrup, P., Ermidis, G. \& Mohr, M. Sodium bicarbonate intake improves high-intensity intermittent exercise performance in trained young men. J. Int. Soc. Sports Nutr. 12, 25 (2015).

31. Ducker, K. J., Dawson, B. \& Wallman, K. E. Effect of beta alanine and sodium bicarbonate supplementation on repeated-sprint performance. J. Strength Cond. Res. 27, 3450-3460 (2013).

32. Miller, P. et al. The effects of novel ingestion of sodium bicarbonate on repeated sprint ability. J. Strength Cond. Res. 30, 561-568 (2016).

33. Griffen, C., Rogerson, D., Ranchordas, D. \& Ruddock, A. Effects of creatine and sodium bicarbonate coingestion on multiple indices of mechanical power output during repeated wingate tests in trained men. Int. J. Sport Nutr. Exerc. Metab. 25(3), 298-306 (2015).

34. Saunders, B., Sale, C., Harris, R. C. \& Sunderland, C. Sodium bicarbonate and high-intensity cycling capacity: variability in responses. Int. J. Sports Physiol. Perform. 9(4), 627-632 (2013).

35. McNaughton, L. R. Bicarbonate ingestion: effects of dosage on 60 s cycle ergometry. J. Sports Sci. 10(5), 415-423 (1992).

36. McKenzie, D. C., Coutts, K. D., Stirling, D. R., Hoeben, H. H. \& Kuzara, G. Maximal work production following two levels of artificially induced metabolic alkalosis. J. Sports Sci. 4(1), 35-38 (1986).

37. Durkalec-Michalski, K. et al. The effect of chronic progressive-dose sodium bicarbonate ingestion on crossfit-like performance: a double-blind, randomized cross-over trial. PLoS ONE. 13(5), e0197480 (2018).

38. Bentzur, K. M., Kravitz, L. \& Lockner, D. W. Evaluation of the BOD POD for estimating percent body fat in collegiate track and field female athletes: a comparison of four methods. J. Strength Cond. Res. 22(6), 1985-1991 (2008).

39. Kyle, U. G. et al. Bioelectrical impedance analysis - part I: review of principles and methods. Clin. Nutr. 23(5), 1226-1243 (2004).

40. Bar-Or, O. The Wingate anaerobic test. an update on methodology, reliability and validity. Sports Med. 4(6), 381-394 (1987).

41. Littell, R. C., Stroup, W. W. \& Freund, R. J. SAS for linear models, 4th Edition. (John Wiley Sons, New York, 2002).

42. Senn, S. Cross-over trials in clinical research. (Wiley \& Sons, London, 2002).

43. Akaike, H. Information theory and an extension of the maximum likelihood principle. (Springer, New York, 1998).

\section{Acknowledgements}

We thank the athletes for their participation and their coaches for help in conducting this research.

\section{Author contributions}

K.D.-M. conceived and designed research. K.D.-M., T.P. and P.M. conducted experiments. K.D.-M., E.E.Z. and B.E.Z. analyzed data. K.D.-M., E.E.Z., B.E.Z., T.P. wrote the manuscript. All authors read and approved the manuscript.

\section{Competing interests}

The authors declare no competing interests.

\section{Additional information}

Correspondence and requests for materials should be addressed to K.D.-M.

Reprints and permissions information is available at www.nature.com/reprints.

Publisher's note Springer Nature remains neutral with regard to jurisdictional claims in published maps and institutional affiliations.

(c) (i) Open Access This article is licensed under a Creative Commons Attribution 4.0 International cc) License, which permits use, sharing, adaptation, distribution and reproduction in any medium or format, as long as you give appropriate credit to the original author(s) and the source, provide a link to the Creative Commons license, and indicate if changes were made. The images or other third party material in this article are included in the article's Creative Commons license, unless indicated otherwise in a credit line to the material. If material is not included in the article's Creative Commons license and your intended use is not permitted by statutory regulation or exceeds the permitted use, you will need to obtain permission directly from the copyright holder. To view a copy of this license, visit http://creativecommons.org/licenses/by/4.0/.

(C) The Author(s) 2020 